\title{
PATTERN OF MEDICATION USE AMONG ELDERLY PATIENTS ATTENDING MEDICINE DEPARTMENT IN A TERTIARY CARE HOSPITAL IN INDIA
}

\author{
SWATHI B*, BHAVIKA D \\ Department of Pharmacology, Osmania Medical College, Koti, Hyderabad, Telangana, India. Email: swathiburlambbs@gmail.com
}

Received: 28 July 2016, Revised and Accepted: 02 August 2016

\section{ABSTRACT}

Objective: The present study was aimed to assess the drug prescribing pattern and analyze the prescribing pattern using Beers criteria among elderly patients aged over 60 years.

Methods: The present study was a prospective observational study conducted in the outpatient Department of General Medicine in a tertiary care hospital for the duration of 3 months. Institutional Ethics Committee approval was taken prior to the initiation of the study. Written informed consent was taken from each study subject. A total of 287 subjects who were aged more than 60 years recruited into the study. The data were collected in a pre-structured case record form. Subjects' demographic details, medical conditions, and drugs included in prescription their dose; frequency, and duration were noted in the case record form.

Results: Among 287 subjects, 91.64\% subjects belonged to 61-70 years age group, remaining 8.36\% subjects were >71 year older, and 57.14\% were males and $42.86 \%$ were females. Hypertension (HTN) was the most common cause of attending hospital followed by diabetes mellitus, central nervous system disorders, respiratory, cardiovascular disorders other than HTN, and infectious diseases. A total of 1574 formulations containing 1669 active ingredients and 90 fixed dose drug combinations were prescribed. And only 152 formulations were prescribed from the outside hospital formulary. The average number of drugs per prescription was $5.48 \pm 2.00$. Among the individual drugs, vitamin B complex was the most commonly prescribed drug.

Conclusion: There is a need for more rational prescribing and to form guidelines for safe and effective use of medicines in elderly patients.

Keywords: Beers criteria, Elderly patients, Drug utilization pattern.

(C) 2016 The Authors. Published by Innovare Academic Sciences Pvt Ltd. This is an open access article under the CC BY license (http://creativecommons. org/licenses/by/4. 0/) DOI: http://dx.doi.org/10.22159/ajpcr.2016.v9i6.14368

\section{INTRODUCTION}

In world, geriatric population occupies significant percentage with over $60 \%$ of the elderly population found in developing countries. The number of elderly persons aged 60 or over in developing countries expected to rise from 510 million in 2011 to 1.6 billion in 2050 [1]. In India, 7.4\% of the population is more than 60 years old, and there is a sharp increase in elderly population in India [2]. It is estimated to rise to $12.4 \%$ by the year 2026 [2]. Elder people constitute a heterogeneous group due to age-related changes in pharmacokinetic and pharmacodynamic profiles of drugs [3]. Age-related changes in body weight, body composition, and decrease in body water and increase in body fat, decrease in renal and hepatic functions alter the pharmacokinetics of drugs. And up regulation and down regulation of the receptors alter pharmacodynamics of drugs and there is increased sensitivity to some of the drugs acting on central nervous system (CNS). Elderly persons use more medications than other age groups. They are associated with higher rates of chronic illness. Most of the elderly live with one or more chronic conditions. Hence, polypharmacy is the most common problem in elderly. Polypharmacy is the use of at least one potentially inappropriate drug or presence of five or more concurrent medications in one prescription $[4,5]$.

Polypharmacy in elderly patients exposes them to increased drug interactions, increased adverse drug reactions (ADRs), and increased health care cost [6]. ADRs are more prevalent in elderly and most are type A reactions predictable from the known pharmacology of the drug and are mostly avoidable [7-9]. Elderly patients also suffer from depression and degenerative diseases such as Alzheimer's disease affecting compliance.

Pattern of drug use, quality of drug use, determinants of drug use, and outcomes of drug use are important insights of drug utilization research. Drug utilization research is defined by the WHO as "study of marketing, distribution, prescription, and use of drugs in society, with special emphasis on the resulting medical, social, and economic consequences" [10]. Drug utilization ultimately assesses whether drug therapy is rational or not.

For the safe and appropriate use of medicines in an elderly, a criteria has been created by Beers [11]. Beers criteria were defined by Beers in 1991 and was updated in 1997, 2003 and 2012. The Beers criteria consist of medications to be avoided in the elderly irrespective of patient's diagnosis, and those that should be avoided due to drugdisease drug-syndrome interactions and those drugs that should be used with caution in older [12]. The Beers criteria also have its deficiencies this led to the development of the newer tools such as the screening tools of older persons prescriptions and screening tool to alert doctors to right treatment $[13,14]$.

The aim of present study was to assess the drug prescribing pattern and analyze the prescribing pattern using Beers criteria among elderly patients aged over 60 years in Osmania General Hospital, Hyderabad, a tertiary hospital.

\section{METHODS}

The present study was a prospective observational study conducted in the outpatient department of General Medicine, Osmania General Hospital, for the duration of 3 months. The study protocol was approved by the Institutional Ethics Committee prior to starting of the study. 287 subjects were included in the study. Written informed consent was taken from each subject before recruiting into the study.

\section{Inclusion criteria}

Subjects who aged more than 60 years and attending medicine outpatient department were included in the study 
Exclusion criteria

Subjects less than 60 years old and who were not willing to give informed consent were excluded from the study.

The data from all the study subjects were collected daily in OP timings, i.e., 9 am to $1 \mathrm{pm}$ in a pre-structured case record form. Subjects demographic details include subject initials, age, gender, socioeconomic status were collected and medical conditions for which the subject was attending the hospital, all investigations, all drugs in the prescription, their dose, duration, frequency were noted in the structured case record form. The subjects were monitored for ADRs.

\section{Data analysis}

Age, gender wise distribution of subjects, frequency distribution of medical conditions, total number of drugs per prescription for each subject, average number of drugs per prescription expressed as mean and standard deviation, number of fixed dose drug combinations (FDCs), number of drugs prescribed from hospital formulary, system wise distribution of drugs, most commonly prescribed drugs in this study and their WHO Anatomical Therapeutic Classification (ATC) defined daily doses (DDDs) were analyzed. Based on the number of drugs in the prescription, they were divided into subjects prescribed with $<5$ drugs, 5-8 drugs and more than 8 drugs. Prescriptions with $>5$ drugs were considered as polypharmacy.

Frequency of prescriptions of potentially inappropriate medications (PIMs) was analyzed using 2012 updated Beers criteria [12].

\section{Statistical analysis}

Mostly descriptive statistics was used. Data were analyzed by the Chisquare test for comparing the proportions of polypharmacy between genders and to test the association between polypharmacy and frequency of prescriptions of PIMs. SPSS software version 24 was used to analyze the data.

\section{RESULTS}

Among 287 subjects who were aged $>60$ years and attending medicine outpatient department, 263 (91.64\%) subjects belonged to 61-70 years age group, remaining $24(8.36 \%)$ subjects were $>71$ years older. The minimum age was 61 years and maximum age 90 years. Out of 287 subjects, $164(57.14 \%)$ were males and 123 (42.86\%) were females. Maximum subjects were attended the department for hypertension (HTN) (63.07\%) followed by diabetes mellitus (DM) $(24.04 \%)$, central nervous system disorders, respiratory, cardiovascular disorders other than HTN, and infectious diseases (Table 1). 130 (45.3\%) subjects had only one condition remaining 157 (54.7\%) had two or more co-morbid conditions.

A total of 1574 formulations were prescribed containing 1669 active ingredients. Of the 1574 formulations, 90 were FDCs and 1484 contained only one active ingredient. And only 152 formulations were prescribed from the outside hospital formulary. The average number of drugs per prescription was $5.48 \pm 2.00$. Out of 287 subjects, 91 (31.71\%) subjects had prescribed with less than 5 drugs, 178 subjects with 5-8 drugs and 18 subjects with more than 8 drugs. The minimum number of drugs per prescription was 1 and the maximum was 12 drugs (Fig. 1).

Polypharmacy is considered as more than 5 drugs per prescription. In this study, polypharmacy was present in 196 (68.29\%) subjects; 84 female and 112 male subjects had polypharmacy (Fig. 2).

The difference in polypharmacy between male and female subjects was not statistically significant $(\mathrm{p}=1.000)$. The system wise distribution of drugs was shown in Table 2. Drugs acting on cardiovascular system (CVS) were the most frequently prescribed drugs (437 subjects), followed by vitamins, minerals, and dietary supplements (302 subjects), drugs acting on gastrointestinal tract (231 subjects), drugs acting on hematological system (126 subjects) together constitutes $69.63 \%$ and others contributes to the remaining $30.37 \%$.
Table 1: Frequency distribution of diseases/conditions

\begin{tabular}{lll}
\hline S. No. & Disease/condition & Number of patients (\%) \\
\hline 1 & HTN (all cases) & $181(63.07)$ \\
2 & DM (all cases) & $69(24.04)$ \\
3 & $\begin{array}{l}\text { HTN+DM } \\
\text { (with or without co } \\
\text { morbid conditions) } \\
\text { Central nervous } \\
\text { system diseases } \\
4\end{array}$ & $66(16.72)$ \\
5 & $\begin{array}{l}\text { Respiratory system } \\
\text { diseases }\end{array}$ & $50(17.42)$ \\
6 & $\begin{array}{l}\text { Cardiovascular } \\
\text { diseases } \\
\text { (excluding HTN) }\end{array}$ & $46(16.03)$ \\
& $\begin{array}{l}\text { Infectious diseases } \\
\text { Other conditions } \\
\text { (renal, endocrine } \\
\text { disorders) }\end{array}$ & $31(10.8)$ \\
8 & $30(10.45)$ \\
& \\
\hline DM: Diabetes & \\
\multicolumn{3}{l}{ mellitus, HTN: Hypertension }
\end{tabular}

Table 2: System wise distribution of drugs

\begin{tabular}{lll}
\hline S. No. & Category of drugs & $\begin{array}{l}\text { Number of } \\
\text { drugs (\%) }\end{array}$ \\
\hline 1 & Drugs acting on cardiovascular system & $437(27.76)$ \\
2 & Vitamins, minerals and dietary supplements & $302(19.19)$ \\
3 & Drugs acting on gastrointestinal system & $231(14.68)$ \\
4 & Drugs acting on hematological system & $126(8)$ \\
5 & Analgesics and anti-inflammatory drugs & $115(7.31)$ \\
6 & Drugs acting on respiratory system & $103(6.54)$ \\
7 & Drugs acting on endocrinal system & $98(6.23)$ \\
8 & Drugs acting on central nervous system & $74(4.7)$ \\
9 & Antimicrobial drugs & $56(3.56)$ \\
10 & Others & $32(2.03)$ \\
\hline
\end{tabular}

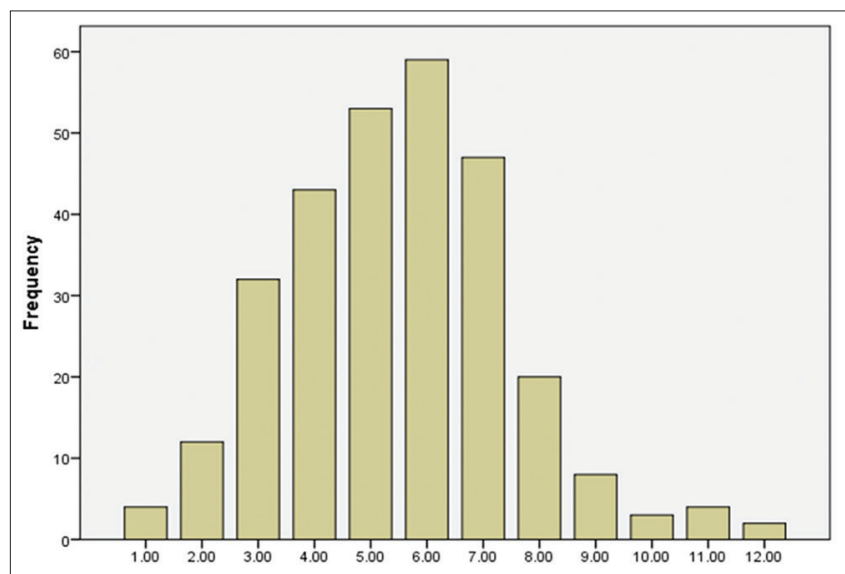

Fig. 1: Frequency of number of drugs per prescription

Vitamin B complex (155 subjects) was the most frequently prescribed drug, followed by enalapril $5 \mathrm{mg}$ (102 subjects), ranitidine $150 \mathrm{mg}$ (101 subjects), pantoprazole $40 \mathrm{mg}$ (94 subjects), amlodipine $5 \mathrm{mg}$ (90 subjects), aspirin $150 \mathrm{mg}$ (81 subjects), calcium lactate $300 \mathrm{mg}$ (76 subjects), atorvastatin (71 subjects), diclofenac sodium $50 \mathrm{mg}$ (61 subjects), and metformin $500 \mathrm{mg}$ (58 subjects). These most commonly prescribed drugs and their ATC code, WHO DDD measure and number of DDDs was shown in Table 3.

Among the antihypertensive drugs, enalapril was the most commonly prescribed drug followed by Amlodipine and among the hypoglycemic agents metformin was the most commonly prescribed drug followed 
Table 3: Most commonly prescribed drugs and their DDD

\begin{tabular}{|c|c|c|c|c|c|}
\hline S. No. & Drug & Number of prescriptions & ATC code & WHO DDD & Number of DDDs \\
\hline 1 & B complex & 155 & A11EA & - & - \\
\hline 2 & Enalapril & 102 & C09AA02 & $10 \mathrm{mg}$ & 42.75 \\
\hline 3 & Ranitidine & 101 & A02BA02 & $0.3 \mathrm{~g}$ & 50.5 \\
\hline 4 & Pantoprazole & 94 & А02BC02 & $40 \mathrm{mg}$ & 94 \\
\hline 5 & Amlodipine & 90 & C08CA01 & $5 \mathrm{mg}$ & 90.5 \\
\hline 6 & Aspirin & 81 & B01AC06 & $1 \mathrm{tab}=1 \mathrm{UD}$ & 81 \\
\hline 7 & Calcium lactate & 76 & A12AA05 & $2 \mathrm{~g}$ & 11.4 \\
\hline 9 & Diclofenac sodium & 61 & M01AB05 & $0.1 \mathrm{~g}$ & 30.5 \\
\hline 10 & Metformin & 58 & A10BA02 & $2 \mathrm{~g}$ & 14.5 \\
\hline
\end{tabular}

DDD: Defined daily dose, ATC: Anatomical therapeutic classification

by glibenclamide. Amoxicillin and potassium clavulanate combination was the most commonly prescribed antimicrobial drug. Deriphyllin (theophylline+etophylline) was the most commonly prescribed among respiratory drugs and phenytoin sodium was the commonly used antiepileptic drug. Total number of injections prescribed was 16, which were injection insulin, deriphyllin, and hydrocortisone.

Out of 1574 formulations, 67 formulations were PIMs identified in 58 subjects according to 2012 updated Beer's criteria. Antihistamines were the most frequently prescribed PIMs (21 subjects), followed by nonsteroidal anti-inflammatory drugs (NSAIDS), digoxin, spironolactone, chlordiazepoxide, amitryptylin, clonidine, alprazolam, amiodarone, phenobarbital (Table 4).

About 50 subjects had only one PIM, 7 subjects had two PIMs and only one subject had three PIMs. There was statistically significant association between polypharmacy and PIMs use in elderly population $(\mathrm{p}<0.05)$.

During the study period, ADRs were recorded in four patients. Three subjects complained of dry cough due to enalapril and one patient complained of gynecomastia due to spironolactone. All were probable according to the WHO causality assessment [15].

\section{DISCUSSION}

Elderly population is growing rapidly in the world, especially in the developing countries. In developing countries persons aged more than 60 years were considered as elderly people. In India, due to low life expectancy compared to developed countries, normal retirement age and eligibility for senior citizenship and according to literature 60 years is considered as cut off age for elderly [16]. Most of the elderly patients suffer from more than one chronic condition and it leads to polypharmacy. This study was undertaken to analyze the prescribing pattern in elderly and problems related to it.

In this study, $57.14 \%$ subjects belonged to male gender, higher than female subjects $(42.86 \%)$. Almost all subjects were uneducated and belonged to low socioeconomic status. The most common condition for attending hospital was HTN; this is similar to other studies conducted in India [17]. Most commonly affected system was CVS followed by CNS and respiratory system. In CVS, most common condition was the HTN followed by coronary artery disease and left ventricular dysfunction. In CNS, cerebrovascular disease was most common, followed by epilepsy. And only $10.8 \%$ subjects had infectious diseases and remaining were non-communicable diseases. This shows an increasing trend of noncommunicable diseases in India.

In the present study, FDCs were only 5.71\%; this was very less compared to other studies [18]. Most common FDCs were deriphyllin (etophylline and theophylline) followed by amoxicillin and potassium clavulanate combination. And $90.34 \%$ drugs were prescribed from the local hospital formulary. This reflects more rational prescribing of drugs.
Table 4: Frequency of the prescription of PIMs

\begin{tabular}{lll}
\hline S. No. & PIMs & Number of drugs \\
\hline 1 & Antihistamines & 21 \\
2 & NSAIDS & 12 \\
3 & Digoxin & 11 \\
4 & Spironolactone & 10 \\
5 & Chlordiazepoxide & 5 \\
6 & Amitriptyline & 3 \\
7 & Clonidine & 2 \\
8 & Alprazolam & 1 \\
9 & Amiodarone & 1 \\
10 & Phenobarbital & 1 \\
\hline
\end{tabular}

PIM: Potentially inappropriate medications, NSAIDS: Non-steroidal anti-inflammatory drugs

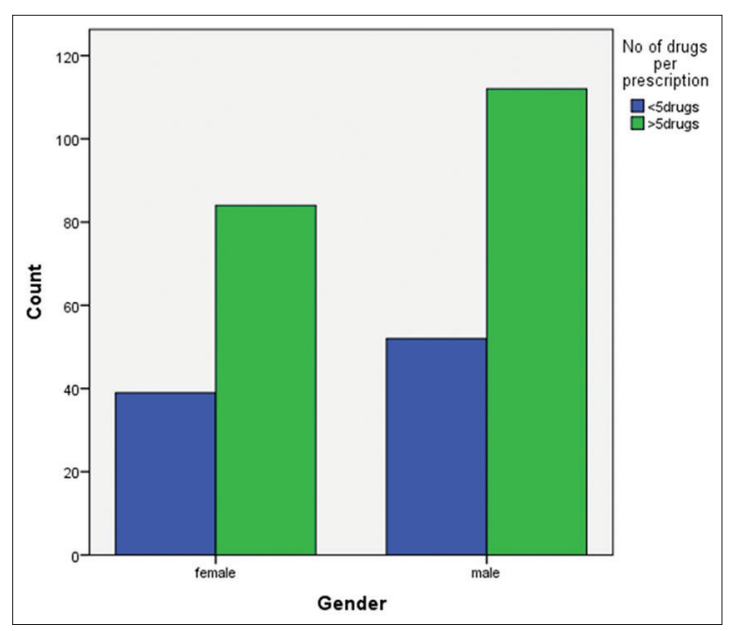

Fig. 2: Polypharmacy in male and female

The average number of drugs per prescription was $5.48 \pm 2.00$, this coincides with other studies [19]. Polypharmacy was present in $68.29 \%$ subjects. In a study by Shah et al., average number of drugs per prescription was $7.3 \pm 4.39$ and polypharmacy was present in $75.25 \%$ patients [20]. Compared to this study, in our study, average number of drugs per prescription and polypharmacy was less. And polypharmacy increases PIMs. This polypharmacy leads to increased health care costs, adverse drug responses, drug interactions, non-adherence, and decline in functional status and cognitive impairment [21]. Hence, measures to control polypharmacy must be taken to avoid consequences.

Clinical trials are done in ideal conditions and mostly involve younger adults. Pharmacokinetics and pharmacodynamics of the drugs are different in elderly population. Hence, there is a need to enroll elderly patients in clinical trials to avoid unnecessary drug related events. Most of the elderly people suffer from hepatic and renal failures so the doses of the drugs that are eliminated by these routes must be adjusted 
accordingly to avoid adverse consequences. In an observational study, for admission into intensive care unit due to unpreventable adverse drug events, compared to controls study group took more number of drugs [22].

Among the drugs, B complex vitamin was the most commonly prescribed drug. According to category wise distribution vitamins, minerals, and dietary supplements were the second most commonly prescribed drugs. Hence, this suggests elderly also suffer from nutritional deficiencies and in our study most complained of generalized body pains. There was increase in the use of drugs that decrease gastric acidity such as ranitidine and pantoprazole. This suggests more number of drugs per prescription led to increased prescription of these gastrointestinal drugs to avoid gastric irritation. Most commonly prescribed cardiovascular drug was enalapril followed by amlodipine. In a study on prescribing patterns of antihypertensive drugs in geriatric patients, most commonly prescribed drug was amlodipine, which was second most common in our study [23]. In the present study, most commonly prescribed drug for type $2 \mathrm{DM}$ was metformin, similar to other study in diabetes patients attending tertiary care hospital in Navi Mumbai [24]. Among antiepileptic drugs, phenytoin was the most commonly prescribed drug despite its various drug-drug interactions. Similarly, phenytoin was the most commonly prescribed drug in a study by Pathak et al. [25].

Beers criteria were used to monitor PIMs in the present study. Antihistamines were the most common PIMs among them, chlorpheniramine maleate was the most commonly prescribed PIM in our study. First generation of antihistamines are included in Beers criteria so other alternative drugs such as second and third generation antihistamines can be used in elderly patients. Second most commonly prescribed PIMs were NSAIDS. Beers criteria suggest that non COX selective NSAIDS must be avoided in high risk groups because these drugs increase gastrointestinal bleeding. Digoxin and spironolactone were prescribed in more than the recommended dosage according to Beers criteria in our study. These drugs must be used in dosage of $<0.125 \mathrm{mg} /$ day and less than $25 \mathrm{mg} /$ day in elderly patients. Antipsychotics, tricyclic antidepressants and barbiturates must be avoided in elderly [12]

\section{CONCLUSION}

The present study analyzed the commonly encountered problems in elderly, number of drugs per prescription, most commonly prescribed drugs and use of inappropriate medication in geriatric patients. So for, safe and effective use of medicines in an elderly, we need guidelines to avoid PIMs and drug related problems. And there is a need for awareness among physicians regarding medication use in elderly.

\section{ACKNOWLEDGMENTS}

I would like to thank all the Teaching Staff and Postgraduates of Department of Pharmacology, Osmania Medical College, Hyderabad, for their kind support without which my work would not have been possible.

\section{REFERENCES}

1. United Nations. World Population Prospects: The 2010 Revision. Available from: http://www.un.org/en/development/desa/ population/publications/pdf/trends/WPP2010/WPP2010_Volume-I_ Comprehensive-Tables.pdf. [Last accessed on 2016 May 30].

2. Situation Analysis of Elderly in India Central Statistics Office, June; 2011. Available from: http://www.mospi.nic.in/mospi_new/upload/ elderly in india.pdf. [Last accessed on 2016 May 30].

3. McLean AJ, Le Couteur DG. Aging biology and geriatric clinical pharmacology. Pharmacol Rev 2004;56(2):163-84.

4. Hajjar ER, Cafiero AC, Hanlon JT. Polypharmacy in elderly patients. Am J Geriatr Pharmacother 2007;5(4):345-51.

5. Kennerfalk A, Ruigómez A, Wallander MA, Wilhelmsen L, Johansson S. Geriatric drug therapy and healthcare utilization in the United kingdom. Ann Pharmacother 2002;36(5):797-803.

6. Gallagher P, Barry P, O'Mahony D. Inappropriate prescribing in the elderly. J Clin Pharm Ther 2007;32(2):113-21.

7. Routledge PA, O'Mahony MS, Woodhouse KW. Adverse drug reactions in elderly patients. Br J Clin Pharmacol 2004;57(2):121-6.

8. Seymour RM, Routledge PA. Important drug-drug interactions in the elderly. Drugs Aging 1998;12(6):485-94.

9. Dormann H, Sonst A, Müller F, Vogler R, Patapovas A, Pfistermeister B, et al. Adverse drug events in older patients admitted as an emergency: The role of potentially inappropriate medication in elderly people (PRISCUS). Dtsch Arztebl Int 2013;110(13):213-9.

10. World Health Organization. Introduction to Drug Utilization Research. Geneva: World Health Organization; 2003.

11. Beers MH. Explicit criteria for determining potentially inappropriate medication use by the elderly. An update. Arch Intern Med 1997; 157(14):1531-6.

12. American Geriatrics Society 2012 Beers Criteria Update Expert Panel. American geriatrics society updated beers criteria for potentially inappropriate medication use in older adults. J Am Geriatr Soc 2012;60(4):616-31.

13. Delgado Silveira E, Montero Errasquin B, Munoz Garcia M, Velez-Diaz-Pallares M, Lozano Montoya I, Sanchez-Castellano C, et al. Improving drug prescribing in the elderly: A new edition of STOPP/START criteria. Rev Esp Geriatr Gerontol 2014 22. pii: S0211139X(14)00223-6.

14. Ubeda A, Ferrándiz L, Maicas N, Gomez C, Bonet M, Peris JE. Potentially inappropriate prescribing in institutionalised older patients in Spain: The STOPP-START criteria compared with the beers criteria. Pharm Pract (Granada) 2012;10(2):83-91.

15. Available from: http://www.who-umc.org/Graphics/24734.pdf. [Last accessed on 2016 May 30].

16. Harugeri A, Joseph J, Parthasarathi G, Ramesh M, Guido S. Potentially inappropriate medication use in elderly patients: A study of prevalence and predictors in two teaching hospitals. J Postgrad Med 2010;56(3):186-91.

17. Fadare JO, Agboola SM, Opeke OA, Alabi RA. Prescription pattern and prevalence of potentially inappropriate medications among elderly patients in a Nigerian rural tertiary hospital. Ther Clin Risk Manag 2013;9:115-20.

18. Jhaveri BN, Patel TK, Barvaliya MJ, Tripathi CB. Drug utilization pattern and pharmacoeconomic analysis in geriatric medical inpatients of a tertiary care hospital of India. J Pharmacol Pharmacother 2014;5(1):15-20.

19. Doubova Dubova SV, Reyes-Morales H, Torres-Arreola Ldel P, Suárez-Ortega M. Potential drug-drug and drug-disease interactions in prescriptions for ambulatory patients over 50 years of age in family medicine clinics in Mexico City. BMC Health Serv Res 2007;7:147.

20. Shah RB, Gajjar BM, Desai SV. Drug utilization pattern among geriatric patients assessed with the anatomical therapeutic chemical classification/defined daily dose system in a rural tertiary care teaching hospital. Int J Nutr Pharmacol Neurol Dis 2012;2:258-65.

21. Maher RL, Hanlon J, Hajjar ER. Clinical consequences of polypharmacy in elderly. Expert Opin Drug Saf 2014;13(1):57-65.

22. Jolivot PA, Pichereau C, Hindlet P, Hejblum G, Bigé N, Maury E, et al. An observational study of adult admissions to a medical ICU due to adverse drug events. Ann Intensive Care 2016;6(1):9.

23. Mohd AH, Mateti UV, Konuru V, Parmar MY, Kunduru BR. A study on prescribing patterns of antihypertensives in geriatric patients. Perspect Clin Res 2012;3(4):139-42.

24. Agarwal AA, Jadhav PR, Deshmukh YA. Prescribing pattern and efficacy of anti-diabetic drugs in maintaining optimal glycemic levels in diabetic patients. J Basic Clin Pharm 2014;5(3):79-83.

25. Pathak S, Singh L, Singh T, Sharma SK. Prescribing patterns of antiepileptic drug in different age group in India. J Drug Discov Ther 2013;1(7):69-75. 